\title{
Reflexões sobre a comunicação em políticas públicas: proposta de um modelo de avaliação da comunicação
} governamental

\author{
Layon Carlos Cezar \\ Universidade Federal de Alfenas / Instituto de Ciências Sociais Aplicadas \\ Varginha / MG - Brasil \\ Universidade Federal do Espírito Santo / Programa de Pós-Graduação em Administração \\ Vitória / ES - Brasil
}

\begin{abstract}
Por entender a comunicação como mediadora para o alcance dos objetivos sociais e governamentais, objetivou-se neste estudo criar e testar um modelo de avaliação da comunicação governamental alicerçado nos pressupostos teóricos do campo. O modelo foi aplicado à análise da Política Nacional de Resíduos Sólidos, uma vez que a mesma enfrenta dificuldades em seu processo de institucionalização ante as diretrizes preconizadas pelo new public management. A partir da análise de conteúdo das entrevistas e de documentos disponibilizados por diferentes atores institucionais no Ministério do Meio Ambiente e em municípios da Zona da Mata Mineira, os dados apontam para a necessidade de um modelo de comunicação particularizado e que não crie estratégias massificadas para gestores, mas que entenda as peculiaridades municipais e regionalismos brasileiros.
\end{abstract}

Palavras-chave: comunicação governamental; new public management; políticas públicas.

\section{Reflexiones sobre la comunicación en las políticas públicas: propuesta de un modelo de evaluación de la comunicación gubernamental}

Mediante la comprensión de la comunicación como un mediador para el logro de los objetivos sociales y gubernamentales, este estudio ambiciona desarrollar y implementar un modelo de evaluación de la comunicación gubernamental fundamentado en las suposiciones teóricas del campo. Se aplicó el modelo en el análisis de la Política Brasileña de Residuos Sólidos, que enfrenta dificultades en su institucionalización por medio de las directrices recomendadas por el new public management. A partir del análisis de contenido de entrevistas y de documentos disponibles (del Ministerio de Medio Ambiente y de los municipios de Minas Gerais), los datos apuntan la necesidad de un modelo de comunicación particularizada que no produzca estrategias macizas para los administradores, sino que entienda las particularidades locales de las múltiples regiones brasileñas.

Palabras clave: comunición gubernamental; new public management; políticas públicas.

\section{Reflections on communication in public policies: proposal for an evaluation model of government communication}

The main proposal of this study is to develop and test an evaluation model of government communication grounded in the field's theoretical assumptions. The model was applied to the analysis of the Brazilian Policy on Solid Waste, given that this policy has encountered problems in its institutionalization process, when considering the new public management guidelines. Content analysis was applied to the interview transcriptions and to the documents released by different institutional actors from the Ministry of the Environment and municipalities in the Zona da Mata of Minas Gerais. From the data analysis, it is concluded that there is a demand for a particularized communication model that does not develop generalized strategies for public managers, but which considers the local peculiarities and the Brazilian regionalism.

Keywords: government communication; new public management; public policy. 


\section{INTRODUÇÃO}

A análise de políticas públicas a partir de perspectivas cíclicas ou em diferentes formatos permite a avaliação de um conjunto de elementos sequenciais responsáveis diretos pela implementação de ações que atendam às demandas estipuladas (Souza, 2006). Em meio a esses processos, a comunicação assume papel fundamental, pois além de permitir a troca dialógica entre os diferentes atores, possibilita o acompanhamento de informações e prestação de contas em cada fase do ciclo.

A comunicação tem se mostrado eficiente, uma vez que, pelos seus inúmeros canais, sobrepuja-se o poder de divulgação das informações e repasse de mensagem ante seu caráter público que estimula a sociedade ao exercício da participação na vida política e nos assuntos com ela relacionados. A comunicação constitui, portanto, desde o processo de formação da agenda para a construção da política pública até o processo de sua implementação e avaliação, um instrumento potencializador da relação entre os atores envolvidos. Sua pretensão primeira é permitir que seus públicos tenham acesso à informação e, consequentemente, despertem seu espírito cívico (Duarte, 2009).

Atualmente o desenvolvimento da new public management trouxe à tona uma série de instrumentos do setor empresarial que no campo da administração pública prezam tanto pela eficiência quanto pela eficácia para a definição de programas, projetos e políticas públicas (Ansell e Gash, 2008; Osborne, 2006). Fundamentado nos pressupostos das ciências gerenciais, a principal proposta desse modelo de administração pública é a valorização de diretrizes mercadológicas destinadas ao estímulo de um Estado mais competitivo, findando o alcance de resultados (Abreu, Hello e Fialho, 2013). Em face das diretrizes desse modelo, torna-se plausível seu desenvolvimento, ao passo que há equilíbrio das demandas sociais ao orçamento governamental. Todavia, conforme relatado por Cezar e colaboradores (2016), no bojo desses processos, ainda que muitas decisões sejam tomadas de forma instrumental e cerceadas por leis específicas, no que tange a seu aspecto público, há uma necessidade de interferência da comunicação, representando, assim, a mola propulsora para o rompimento do formalismo.

Nesse ínterim, a comunicação assume seu caráter de comunicação governamental, criando mecanismos para inaugurar e manter espaços voltados à participação popular, adequando seu conjunto de mídias aos públicos receptores dessas informações e repassando informações técnicas quanto a prazos e objetivos de determinada política pública, campanha ou plano de governo (Vos, 2006; Cezar et al., 2016). Ainda que em tempos de busca pela eficiência e eficácia seja complexo visualizar amplas formas de participação, Henriques e colaboradores (2002) destacam que compreender a comunicação em tais circunstâncias torna-se fundamental para a identificação dos atores envolvidos e os vínculos estabelecidos, além dos ideais propostos.

A comunicação atua então nas políticas públicas como um meio necessário para a divulgação das etapas e a mobilização dos envolvidos. Seu objetivo principal é a diminuição das barreiras entre governantes e governados, no intuito de disseminar as informações contidas e preconizadas em lei (Saldanha, 2006). O objetivo ao repassar tais informações centra-se na importância de cumprir as metas estipuladas e buscar solucionar determinada situação, vivenciada no âmbito do espaço público. Ao mencionar o espaço público como meio para a troca argumentativa, assume-se a perspectiva levantada por Habermas (1984) do espaço como meio de visibilidade e busca pelo melhor argumento.

Ante o exposto, tornou-se pertinente questionar como a comunicação governamental pode ser avaliada nos parâmetros de eficiência e eficácia preconizados pelo new public management? Os 
atuais modelos de avaliação da comunicação encontrados na literatura organizacional centram-se nas discussões de Galerani (2006), Henriques e colaboradores (2002) e Vos (2006); todavia a necessidade de utilizar um modelo específico à comunicação governamental levou à criação de uma metodologia própria baseada na literatura do campo. O modelo preconizado por Cezar (2014) considera elementos de publicização, formalização e operacionalização para análise desse viés da comunicação.

Assim, o modelo desenvolvido aplica-se no estudo da Política Nacional de Resíduos Sólidos (PNRS) criada em 2010, via articulação do Ministério do Meio Ambiente (MMA), com objetivo principal de eliminar os lixões do Brasil até 2014. Todavia, desde sua criação, a PNRS vem enfrentando inúmeros problemas em seu processo de implementação e, consequentemente, barreiras à institucionalização. Pressupõe-se que, entre as inúmeras dificuldades para o alcance das metas, a comunicação governamental assume papel fundamental, uma vez que a não institucionalização da política pode revelar, em seu cerne, dificuldades de comunicação.

\section{COMUNICAÇÃO GOVERNAMENTAL, NEW PUBLIC MANAGEMENT E A ESFERA PÚBLICA}

O avanço da comunicação governamental (CG) com campo de estudo emancipado da comunicação organizacional acontece no final da década de 1980, dado o fortalecimento do espírito de cidadania emerso de uma sociedade civil mais organizada e consciente dos seus direitos e deveres. A partir da comunicação governamental como área merecedora de maiores incentivos nas organizações públicas, observa-se ao longo do tempo a criação de estruturas voltadas para a divulgação de informações de cunho público pelos poderes executivos, desenvolvendo identidade na prestação de contas à sociedade (Torquato, 2009). Assim, a CG como campo de estudos ganha notoriedade, ao passo que investigações concebem não somente a visão funcionalista do processo comunicacional, mas suas vertentes estruturais, interpretativas e críticas, imbuídas no bojo político.

Ainda que se navegue em um campo contestável, é plausível a adoção do conceito de comunicação governamental como a comunicação exercida entre e para com o Estado, as instâncias de governo e a sociedade. No entanto, o conceito está além dessa definição funcional e simplificada, conforme enfatizado:

A comunicação governamental pode ser entendida como comunicação pública, na medida em que ela é um instrumento de construção da agenda pública e direciona seu trabalho para a prestação de contas, o estímulo para o engajamento da população nas políticas adotadas, o reconhecimento das ações promovidas nos campos políticos, econômico e social, em suma, provoca o debate público. Trata-se de uma forma legítima de um governo prestar contas e levar ao conhecimento da opinião pública projetos, ações, atividades e políticas que realiza e que são do interesse público. [Brandão, 2009:5]

No Brasil, o discurso e o propósito adotados pelo governo quanto à prática da comunicação governamental norteiam-se (ou deveriam) no exercício do princípio constitucional da publicidade na administração pública (Brasil, 1988: art. 37). Os gestores públicos buscam desenvolver um governo pautado na transparência e na accountability. O discurso da accountability deve se estabelecer aqui não como um sistema fechado de transparência ou repasse de informações públicas, mas como uma 
forma de empoderar a sociedade civil e os diferentes atores envolvidos, sendo estes capacitados e estimulados a participarem do planejamento e das decisões governamentais.

Nesse processo de comunicação governamental, a busca pela maximização de resultados a partir de um fluxo comunicacional bem estabelecido e que garanta maiores possibilidades de resultados para o governo e a sociedade vem ao encontro dos objetivos de eficiência e eficácia do setor público, preconizados pelo new public management. Ao apoiar-se em uma concepção neoliberal e entender que o Estado deva privar pela maximização de resultados em todos os setores, a CG nesse meio deve atingir o objetivo proposto de forma que seus atores possam participar independentemente da arena ou canal de comunicação criado. Segundo Hood (1995), na busca pela eficiência e promoção da equidade, o Estado consequentemente preza pela melhoria na prestação de serviços.

Cabe então destacar que a CG, vista na ótica do NPM, age como um conjunto de procedimentos e normas, ao passo que estimula a criação de espaços e diretrizes para a atuação do Estado como meio para que arenas de debates sejam formadas, formalizadas e institucionalizadas (Stoker, 1998). A essas arenas cabe a discussão para a busca de argumentos que interfiram na ordem da vida pública, criando assim planos, metas, responsabilidades e prazos para que a participação não seja fruto apenas de discussões, mas medida de resultados a serem colhidos a partir da verdadeira contribuição nas ações.

Para Hughes (2010), a NPM atualmente é considerada um movimento que perdeu sua força à proporção que as instituições públicas passaram a enxergá-la mais como uma ideologia do que realmente como uma diretriz metodológica que poderia interferir como governança em seu sentido lato sensu. Hughes (2010), citando Osborne e Gaebler (1992), compartilha a visão dos autores acreditando que atualmente há uma emersão de um novo ideal caracterizado como new public governance (NPG), em que a governança é o elemento central na delimitação da atuação do Estado como articulador de instrumentos, concepções e diretrizes em prol da sociedade. Autores como Ansell e Gash (2008) e Osborne (2006) acreditam que a NPG se encontra em amplo processo de expansão ante os novos modelos participativos.

Assim, em meio a esse novo formato de governo que permeia entre o modelo da NPM preconizado pela eficiência e eficácia e o modelo de caráter mais participativo da NPG, a CG adquire caráter central, ao permitir ao cidadão, como participante direto do processo de controle das políticas públicas, a criação de vínculos com as causas demandadas e com o histórico de participação (Henriques et al., 2002).

Ao se compreender, todavia, o papel da comunicação, torna-se fundamental entender não somente suas funções e seus instrumentos, mas os atores que constituem as arenas de debates e a esfera pública. De acordo com Arendt (2007), compreender o verdadeiro significado do cidadão como pertencente ao campo do diálogo na esfera pública é permitir a conversação e a troca argumentativa em busca de proposições que garantam um debate saudável.

O debate, no entanto, deve ser visto como algo para além do diálogo e, como apontado por Habermas (1984), espaço em que os indivíduos compartilham suas afirmações e objeções, caminhando para posicionamentos que realmente contribuam para a busca de soluções à vida pública. Tal concepção da vida pública adquire seu caráter cada vez mais amplo de acordo com o aperfeiçoamento e o surgimento de novos espaços convencionais de participação, ampliando os discursos sociais na definição de seus interesses (Gomes, 1998). 
De acordo com Bohman (2009), a comunicação transforma-se em espaços de diálogo na esfera pública, à medida que é permissível a seus atores entender o contexto de publicidade forte e fraca desenvolvido muitas vezes de forma involuntária. Segundo o autor, a publicidade forte acontece quando as ações são discutidas em sentido ampliado para que as razões não sejam apenas instrumentalizadas, mas discutidas até o encontro de alternativas mais viáveis. A publicidade fraca, por sua vez, acontece quando os envolvidos aceitam uma lógica engessada, concordando ou discordando dos pontos apresentados. Nessa esfera, as discussões não são tão profícuas e os cidadãos agem com players em um jogo. Sua participação é necessária mais para compor o grupo do que realmente instigar alguma manifestação de interesses.

Independentemente das instâncias formadas, o foco da CG é o repasse de informações à população no intuito de gerar algum tipo de argumentação para o uso nos espaços de diálogo. Essas instâncias de diálogos visam então atender às demandas da sociedade por participação, almejando o alcance de seus objetivos. Objetivos que não deveriam adquirir uma razão instrumentalizada, mas uma razão construída mediante amplas esferas de diálogos (Bohman, 2009). Contudo, para que todo o caminho descrito possa ser entendido e que realmente a população participe da esfera pública como cidadãos legítimos, a publicização desses espaços é condição para que as discussões sejam proveitosas. Entende-se aqui a publicização como a capacidade de tornar as informações públicas. Tais informações devem apresentar os espaços necessários às instâncias de diálogo à população, convidá-la a participar e envolvê-la nas discussões da vida pública (Henriques et al., 2002).

\section{CAMINHOS METODOLÓGICOS}

A caracterização do presente estudo quanto à sua natureza centra-se em abordagem de caráter predominantemente qualitativo. Em relação aos meios, a pesquisa pode ser classificada como pesquisa de campo e documental. De acordo com Gil (1991), a pesquisa de campo busca aprofundar-se em realidades específicas por meio de observações e entrevistas diretas a determinado público, com o propósito de entender explicações e interpretações. Por outro lado, a pesquisa documental pode ser explicada, de acordo com Santos (2000), como um tipo de pesquisa realizada por meio de documentos atuais ou antigos, mas que possuam caráter científico autêntico.

Em relação aos objetivos, esta pesquisa caracteriza-se tanto como exploratória quanto descritiva. Acredita-se que o estudo, além de descrever e explorar o conteúdo das entrevistas por meio de análises fundamentadas na teoria, propõe uma nova visão sobre o problema investigado, trazendo à luz elementos que possam auxiliar na ampliação das formas de comunicação da PNRS.

Para a coleta de dados nesta pesquisa, tornou-se necessária a utilização de dados primários (entrevistas) e secundários (documentos). As entrevistas foram realizadas em nível governamental, direcionadas a membros da Secretaria de Recursos Hídricos e Ambiente Urbano (SRHU) e à Assessoria de Comunicação (Ascom) do Ministério do Meio Ambiente (MMA), situado em BrasíliaDF, e em autarquias e/ou secretarias de meio ambiente dos maiores municípios da Zona da Mata Mineira (IBGE, 2010). Foram entrevistados secretários municipais de meio ambiente e em alguns casos diretores das autarquias municipais ligadas ao saneamento básico das cidades de: Cataguases, Juiz de Fora, Manhuaçu, Muriaé, Ponte Nova, Ubá e Viçosa. A justificativa para a escolha desses sujeitos explica-se devido à necessidade de avaliar as respectivas percepções dos principais tomadores de decisões relacionadas com a questão da comunicação. Os dados secundários, por sua vez, 
se constituíram a partir da utilização de bases específicas como o Instituto Brasileiro de Geografia e Estatística (IBGE), o Sistema Nacional de Informações sobre Resíduos Sólidos (Sinir), o Sistema Nacional de Informações sobre Saneamento (Snis), além de sites do Ministério do Meio Ambiente, Ministério das Cidades, atas, jornais, cartilhas e publicações internas das organizações investigadas, sendo utilizados tanto para fundamentar a construção da investigação, quanto para a compreensão de elementos não esclarecidos nas entrevistas.

Os dados primários coletados no Ministério do Meio Ambiente tornaram-se possíveis a partir do uso do software Skype ${ }^{\circledR}$. Utilizou-se também do e-mail como forma de coleta dos dados no MMA. Nas cidades em estudo, os dados foram coletados por meio de entrevistas realizadas na sede das próprias secretarias de meio ambiente e em alguns casos nas autarquias municipais responsáveis pelo gerenciamento das questões ligadas aos resíduos sólidos. Preservando os dados e o sigilo quanto às informações dos respondentes da pesquisa e à identificação dos mesmos, criou-se uma denominação de G1 (representante 1 do governo federal) e G2 (representante 2 do governo federal) para representantes do MMA e M1 (representante do governo municipal - cidade 1), M2 (representante do governo municipal - cidade 2), M3 (representante do governo municipal - cidade 3), M4 (representante do governo municipal - cidade 4), M5 (representante do governo municipal - cidade 5), M6 (representante do governo municipal - cidade 6) e M7 (representante do governo municipal - cidade 7) para os respondentes dos municípios em foco.

A análise dos dados foi realizada pelo método denominado análise de conteúdo, em que há um desmembrar do texto em unidades, objetivando fornecer representação simplificada dos dados brutos (Bardin, 1977). Visando traçar um paralelo entre o discurso do MMA e dos municípios em estudo, os dados foram analisados de forma comparativa. Cabe enfatizar que, para a realização da análise de conteúdo deste estudo, utilizou-se do software $\mathrm{NVivo}^{\circledR}$ 9. A partir do uso do software, foi possível estratificar o conteúdo das entrevistas em categorias, fazer a leitura dos dados e separá-los por subcategorias.

Devido às dificuldades de se encontrarem modelos específicos de avaliação da comunicação governamental, criou-se um modelo teórico operacional a partir das contribuições teóricas do campo. O modelo criado propõe uma investigação a partir de três categorias: publicização, formalização e operacionalização. A partir da identificação de elementos centrais e da reunião em categorias, tornou-se convencional agrupar tais elementos em um modelo no qual se busca o atendimento a três requisitos para concluir se há eficiência e eficácia da comunicação governamental, como explanado na figura 1.

O conceito de publicização adotado entende a publicidade como um meio para possibilitar que as informações sobre determinada política sejam conhecidas pelos públicos a partir de interações dialógicas, garantindo que todos os interlocutores participem com efetividade nas arenas de debates, presentes desde a "eficiência técnica", a "eficácia instrumental", chegando à concreta efetividade "da cidadania", alcançando a "relevância do humano" e sua "legitimação no Mundo da Vida", fundamentando-se nas contribuições encabeçadas por Habermas (1990) e Bohman (2009). Tal análise possibilita a verificação quanto ao grau de publicização das informações, caracterizando como forte ou fraco, levando em conta a inserção dos atores em foco em contextos participativos. Os elementos centrais investigados estão situados no entendimento dos contextos democráticos de participação, na interação entre os atores e na publicização das ações. 


\section{FIGURA 1 MODELO TEÓRICO OPERACIONAL}

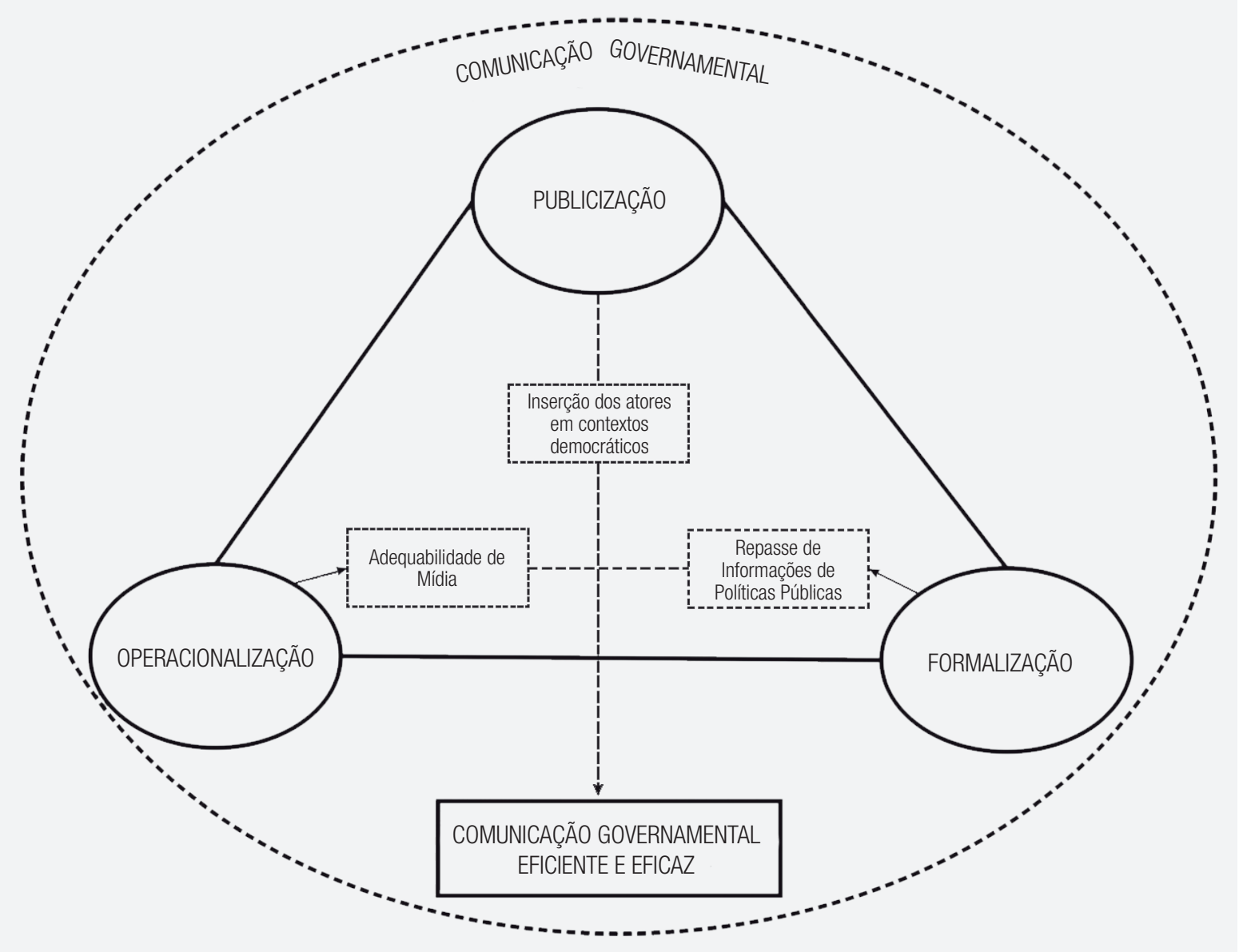

Fonte: Cezar (2014).

O critério de formalização entende a CG como um processo de caráter utilitarista em que informações pontuais devem ser repassadas em parâmetros objetivos aos seus públicos. Nesse caso, centra-se a análise sobre a divulgação de prazos, formas de acesso a recursos, campanhas, entre outras informações necessárias para a implementação da política pública. Tal formalização deve estabelecer-se de forma pontual, em que o emissor envia uma mensagem direta ao receptor sem que haja interpretações equivocadas, permitindo que ambas as partes sejam compreendidas. Os elementos centrais investigados centraram-se no entendimento do planejamento das estratégias de comunicação, na eficácia quanto ao alcance das metas, no repasse de informações pontuais da política pública e nos canais de feedback.

A operacionalização, por sua vez, considera a adequabilidade de mídias ante seu público-alvo. A comunicação atinge aqui seu papel operacional, ao passo que se utiliza das ferramentas midiáticas adequadas para tornar públicas suas informações. $\mathrm{O}$ uso adequado de mídias acontece na medida em que o receptor tem condições de decifrar as mensagens enviadas a partir das mídias a que tem acesso e que são priorizadas pelo emissor. Os elementos centrais investigados centram-se no entendimento das mídias disponíveis, da adequabilidade ao público-alvo e de aspectos que influenciam a comunicação da política pública. 


\section{RESULTADOS E DISCUSSÕES}

\subsection{PERFIL DOS MUNICÍPIOS}

Segundo informações de Brasil (2013) e Cezar (2014), em Minas Gerais apenas quatro municípios apresentam propostas de Plano de Gestão dos Resíduos Sólidos dentro do prazo estipulado. A região da Zona da Mata, por sua vez, é a terceira mais populosa do estado, com 11,9\% do total de habitantes (IBGE, 2010), e, no entanto, nenhum município apresentou o plano dentro do prazo estipulado. Dessa forma, fundamentando-se nos dados secundários, tornou-se imperativo traçar um perfil dos municípios investigados, considerando que a pesquisa foi realizada na cidade que representa cada uma das sete microrregiões, conforme disposto na tabela 1.

\section{TABELA 1 PERFIL DOS MUNICÍPIOS}

\begin{tabular}{|c|c|c|c|c|c|c|c|}
\hline Município & IDH & População & $\begin{array}{c}\text { PIB per } \\
\text { capita (R\$) }\end{array}$ & $\begin{array}{l}\text { Competência pela } \\
\text { gestão e ou execução } \\
\text { do serviço }\end{array}$ & $\begin{array}{c}\text { Forma de } \\
\text { Destinação do } \\
\text { RS1 }\end{array}$ & $\begin{array}{l}\text { Coleta } \\
\text { Diferenciada } \\
\text { do RSS2 }\end{array}$ & Despesas (R\$)3 \\
\hline Cataguases & 0,751 & 69.757 & $14.983,13$ & Administração Direta & $\begin{array}{c}\text { Aterro } \\
\text { Sanitário }\end{array}$ & - & - \\
\hline Juiz de Fora & 0,778 & 516.247 & $16.054,99$ & $\begin{array}{l}\text { Administração Direta } \\
\text { Autarquia Municipal }\end{array}$ & $\begin{array}{c}\text { Aterro } \\
\text { Sanitário }\end{array}$ & Sim & $24.699 .958,58$ \\
\hline Manhuaçu & 0,689 & 79.574 & $14.102,84$ & Autarquia Municipal & Lixão & Não & $2.478 .600,00$ \\
\hline Muriaé & 0,734 & 100.765 & $10.712,78$ & $\begin{array}{l}\text { Administração Direta } \\
\text { Autarquia Municipal }\end{array}$ & Lixão & Sim & $4.878 .925,32$ \\
\hline Ponte Nova & 0,717 & 57.390 & $13.767,79$ & Administração Direta & Lixão & - & - \\
\hline Ubá & 0,724 & 101.519 & $13.564,99$ & Administração Direta & $\begin{array}{c}\text { Aterro } \\
\text { Sanitário }\end{array}$ & - & - \\
\hline Viçosa & 0,775 & 72.220 & $9.597,12$ & Autarquia Municipal & $\begin{array}{c}\text { Aterro } \\
\text { Controlado }\end{array}$ & Sim & $2.797 .824,91$ \\
\hline
\end{tabular}

Fonte: Cezar (2014).

Notas: ${ }^{1} \mathrm{RS}$ - Resíduos Sólidos; ${ }^{2} \mathrm{RSS}$ - Resíduo de Serviço de Saúde; ${ }^{3}$ Despesa total com serviços de manejo de RSU — Resíduos Sólidos Urbanos (público + privado + outros executores).

Depreende-se o destaque do município de Juiz de Fora, uma vez que, além de possuir maior população, PIB e IDH da região, possui ampla infraestrutura para a gestão e o gerenciamento dos resíduos sólidos. O município conta com a Secretaria de Meio Ambiente para gestão de informações ligadas aos resíduos sólidos e da autarquia municipal para execução dos serviços. Destacase, ainda, a correta destinação de resíduos via aterro sanitário, que contribui para o descarte de seu próprio resíduo e de mais 10 municípios vizinhos. Além da coleta diferenciada dos resíduos de serviços de saúde e, consequentemente, o maior volume de despesas dos serviços de manejo de RSU, Juiz de Fora cumpre suas exigências, uma vez que toda estrutura atende às requisições instituídas pela PNRS. 
Sobre os demais municípios, nota-se a administração direta como a grande responsável tanto pela gestão como pela execução dos serviços de resíduos sólidos. Tal fato pode implicar diretamente a sobrecarga quanto ao volume de atividades, impedindo assim que ações mais expressivas possam ser alcançadas. A distribuição de atividades ocorre em parceria entre secretarias de meio ambiente e autarquias responsáveis pela execução dos serviços, que, se bem articuladas, podem auxiliar quanto a essa questão. Todavia, em relação às formas de destinação dos resíduos sólidos, o lixão é a forma de destinação dos resíduos em três municípios e o aterro controlado, de um deles, representando ainda formas primitivas que não atendem às metas preconizadas pela PNRS.

\subsection{CATEGORIAS DE ANÁLISE DO MODELO TEÓRICO OPERACIONAL}

\subsubsection{PUBLICIZAÇÃO}

A Política Nacional de Resíduos Sólidos surge em 2010 após anos de discussões e a partir da dificuldade de atendimento à questão do lixo pela Política Nacional de Saneamento Básico (Lei no 11.445) criada em 2007. De acordo com G2, a PNRS tramitou por quase 20 anos no Congresso, e durante esse período inúmeros avanços podem ser avaliados na tentativa de organização do espaço, aguardando sua sanção. G1, por sua vez, destaca o papel de vários outros órgãos, políticas públicas e ministérios para a construção e implementação da política pública, conforme destacado na figura 2.

\section{FIGURA 2 AÇÕES QUE CULMINARAM NA CRIAÇÃO DA PNRS}

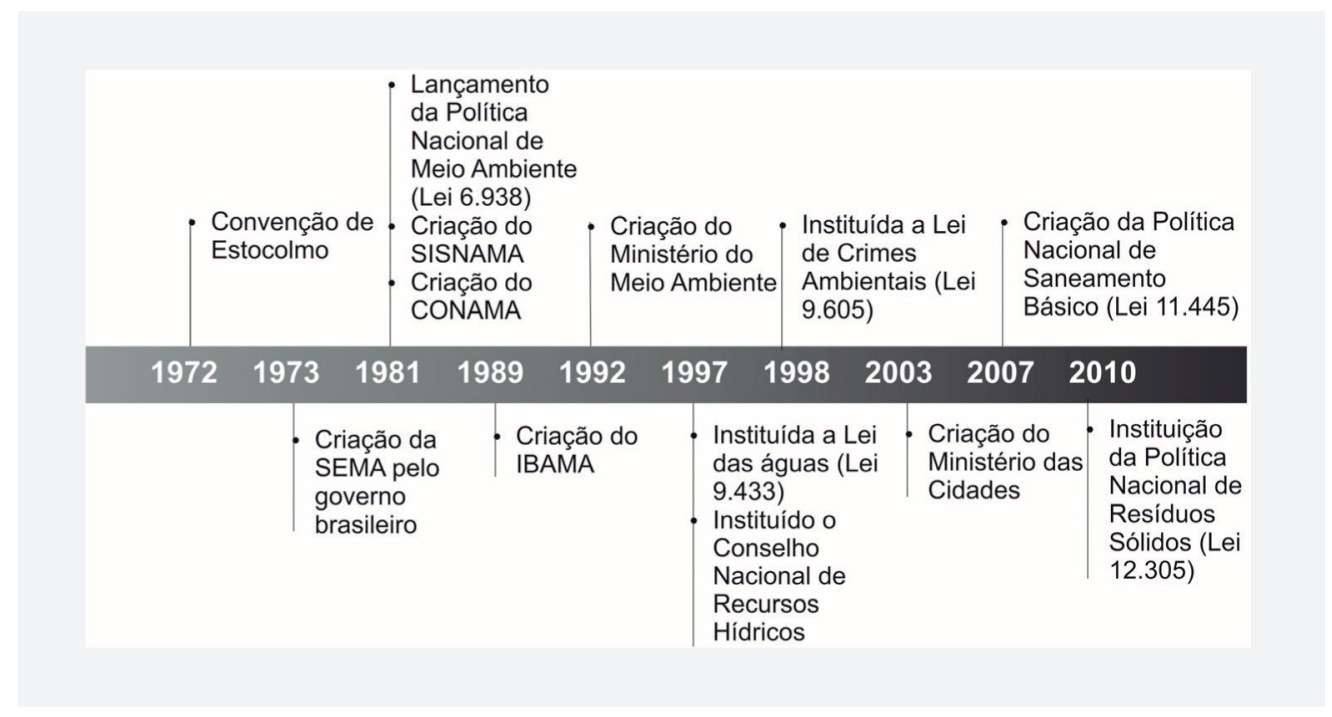

Fonte: Cezar (2014).

No intuito claro em sua concepção de acabar com todos os lixões do Brasil até 2014, a política envolve em seu texto um conjunto de diretrizes necessárias para a construção de aterros sanitários, 
formas de financiamento dessa infraestrutura, estímulo à coleta seletiva, criação da logística reversa, estímulo à formação de cooperativas e associações de catadores, incentivo na formação de consórcios intermunicipais, entre outras questões. Dado a gama de assuntos, pressupôs-se participação nos espaços deliberativos durante o período de elaboração da política pública. Tal premissa foi negada, conforme os relatos de M1 e M2.

[...] na elaboração da Política Nacional de Resíduos Sólidos a gente não teve participação, até porque no período em que foi efetuado esse planejamento a gente não tinha uma secretaria constituída, de fato, o nosso corpo técnico era micro, era só pra atender as demandas internas nossas aqui, entendeu? [M1]

Essa participação "pré-teste" é lá, eu não posso nem te falar, mas nós vamos ter uma participação futura, né, justamente na conferência, né. [M2]

Grande parte da dificuldade quanto à inserção nestes espaços iniciais justifica-se, por um lado, diante da demora de sanção da lei e, por outro, dada a dificuldade técnica das secretarias de meio ambiente, uma vez que não tinham conhecimento desses espaços ou não contavam com corpo técnico suficiente para buscar tais informações.

Atualmente, a questão da participação também tem se configurado como um problema, conforme destacado nos discursos de M1, M3 e M5:

A gente tinha algumas ações, mas isoladas, por exemplo, a gente executava aqui o Fórum Municipal de Lixo e Cidadania, entendeu, participava, às vezes, do Fórum Estadual, mas isso era muito esporádico. E o Fórum Municipal, é, participava como convidado, a gente também não repassava as informações pros níveis estaduais e federais, então, a gente nem pode falar que participou [...] a gente estava tão voltado pra questão interna nossa aqui pros, entendeu, que em âmbito regional a gente não participava, quanto mais federal [...] Eu sei que teve, tiveram alguns fóruns, né, alguns, é, como é que é o nome, gente, que teve lá, algumas conferências. [M1]

Não, na verdade, por termos poucas informações, realmente dificultou. [M3]

[...] Então, a gente, a nossa participação é muito mais com relação a essas obrigatoriedades que a gente precisa cumprir [...] A gente tá aqui pra cumprir muita das vezes, né, muito uma questão mais, é, impositiva mesmo, né. [M5]

Os discursos revelam a participação regionalizada em que as iniciativas ou são municipais ou são estaduais. A participação dos espaços institucionais em nível federal praticamente não ocorre, segundo os entrevistados, por falta de informações sobre quais são, onde estão e quais as formas de participação dos mesmos. Paralelamente, o relato de M5 destaca o caráter instrumental da participação, resumindo-a a relatórios entregues pelas exigências governamentais, enfraquecendo assim o caráter participativo em face das exigências burocráticas. 
O discurso governamental, por sua vez, não compartilha a visão dos entrevistados, uma vez que destaca a participação criada e estimulada a partir de debates em arenas estaduais de governo, como relatado no discurso de G1:

A gente teve participação com o governador [...] na cidade administrativa, a gente teve vários debates ali [...] Tem milhão de municípios aí em Minas Gerais, mas muito presente, muito participativo, isso é muito bacana [...]. [G1]

O espaço criado para o debate (físico e institucional) a partir da articulação com o governo de Minas Gerais pode ter envolvido inúmeros representantes de municípios mineiros; todavia, os principais representantes das maiores cidades da Zona da Mata não compartilham tal percepção. Acredita-se que a centralização dos debates na sede do governo mineiro de certa forma pode ter inibido a participação de alguns atores.

\subsubsection{FORMALIZAÇÃO}

Entendendo que a comunicação, ao adquirir seu caráter de formalização, se estabelece a partir de um fluxo em que a comunicação parte de um receptor, configura-se a partir de símbolos, findando-se no receptor e no feedback do mesmo, investigou-se aqui o repasse de informações advindas de gestores que ocupavam as secretarias ambientais anteriormente à entrada dos atuais. Posteriormente, analisou-se a estratégia de comunicação utilizada pelo MMA, o entendimento dos atuais gestores sobre a mesma e o feedback estabelecido entre município, governo e sociedade.

O repasse de informações de gestões anteriores nas autarquias municipais poderia agilizar o fluxo de informações e de certa forma criar um alicerce de conhecimento para que os atuais gestores pudessem compreender melhor as diretrizes da PNRS. Todavia, os discursos deles revelam que o repasse não ocorreu principalmente devido à troca de prefeito e da equipe vinculada a ele. Tal fato evidencia que ainda que a NPM se mostre presente na atual administração pública brasileira, traços de patrimonialismo dificultam a implementação de políticas públicas descentralizadas.

Ao se verificar o repasse de informações sobre a PNRS, tornou-se possível identificar um hiato de diferenças entre o discurso governamental e o discurso dos representantes municipais. Inicialmente, a verificação centrou-se na estratégia de comunicação utilizada pela MMA para divulgação da política pública e suas respectivas prioridades. O discurso de G1 revela as diferentes estratégias.

[...] a gente trabalha nessa primeira perspectiva, então qual que é o primeiro foco: informar as pessoas que a política estava aí, que foi aprovada e qual era o conteúdo dela. Num segundo momento tratar da importância, tratar da separação dos resíduos, primeiro entender o que é resíduo sólido urbano, qual a importância disso para o meio ambiente, para própria sociedade, qual o papel dos catadores nesse processo [...]. Então no momento atual, o que a gente quer? A gente já sabe o que tem para fazer, este terceiro momento é de como fazer [...] Então a gente vem trabalhando isso, as etapas, porque trabalhar a política como um todo não seria tão eficiente, né, dessa forma. [G1]

Conforme explanado, a estratégia de comunicação foi elaborada no intuito de repassar informações gradativas da PNRS. No discurso de G1, torna-se notório que as etapas de divulgação da 
política pública foram implementadas na medida em que o MMA acreditava que a população estava entendendo as informações. No primeiro momento, tornou-se necessário uma explanação ampla da política pública no intuito de comunicar que ela foi aprovada e qual seu conteúdo. Posteriormente, buscou-se trabalhar junto à sociedade conceitos mais técnicos, ligados às formas de separação do lixo, bem como o entendimento de alguns conceitos-chave e o papel dos empreendimentos de catadores nesse processo.

Nessa segunda etapa de divulgação, G2 destaca a importância de se utilizar uma linguagem de fácil compreensão:

Porque essa área de resíduo, eu como jornalista quando me deparei, a área técnica é composta por engenheiros [risos] e falam uma linguagem muito técnica que para eles é muito usual, comum no dia a dia, e eu preciso de uma tradução, eu falei, se eu conseguir entender, a gente precisa trabalhar uma linguagem que eu entenda e que o pessoal da limpeza que está aqui tenha entendimento também [...]. Então não adianta, não é pra envolver apenas pessoas de um nível de instrução mais elevada, mas é para todo mundo. Porque principalmente as classes C e B são as que mais consomem hoje e são as que mais geram resíduos [...]. [G2]

Percebe-se que um dos grandes objetivos se centra na tentativa de clarificar o conteúdo e o entendimento do público-alvo, uma vez que tal interpretação não poderia ocorrer de forma setorizada, atendendo apenas aos conhecedores da temática. Assim, investigou-se junto aos representantes municipais o conhecimento de metas e prazos. Os discursos relatam o quão as metas estão difundidas nos discursos governamentais e, ainda que não a conheçam em sua totalidade, há uma menção direta aos seus principais objetivos:

Então, eu tenho algumas metas, né, como a erradicação de lixões, né, implantação de programas coleta seletiva, é, a implantação de logística reversa, né, de alguns produtos, isso a gente tem conhecimento. [M1]

[...] Nós temos conhecimento, é, a questão de, por exemplo, acabar com os lixões [...] Então hoje, nós temos que elaborar um novo, uma nova área, adquirir um novo terreno, pra que a gente possa fazer um aterro sanitário de forma controlada, de acordo com as metas e obrigações com o meio ambiente. [M3]

[...] A gente tem conhecimento que a gente tem que ter o, o aterro sanitário, né, tem que fazer, trabalhar reciclagem de lixo, fazer, né, o lixo reciclado, é, temos conhecimento de que também a, os lixos dos grandes geradores é uma responsabilidade do grande gerador [...]. [M4]

[...] vinculados a política, temos o programa, né, Minas Sem Lixões, também de Minas. É, em 2011 o município já procurou adequar todo seu, nós não possuímos mais o lixão. Temos a coleta seletiva implementada, plano de saneamento básico também a gente já tá trabalhando. [M6]

Como se observa nesses discursos, o conhecimento da meta principal (acabar com os lixões e construir aterros sanitários) vem sendo amplamente divulgado e os gestores têm plena consciência 
de seus deveres; todavia nota-se no discurso de M6 certa confusão ao relacionar a PNRS ao Programa Minas Sem Lixões ${ }^{1}$ desenvolvido pelo governo de Minas Gerais. Tal fato pode evidenciar a necessidade de um modelo de comunicação que esclareça as particularidades da comunicação em nível federal e a comunicação em nível estadual.

Em relação aos prazos, grande parte dos entrevistados em nível municipal relata a dificuldade de conhecimento de informações técnicas para organização do Plano Municipal de Gestão dos Resíduos Sólidos e das formas de acesso aos recursos financeiros para implementação das ações da PNRS. Tal fato pode ser observado no discurso de M5:

[...] isso já vem divulgado há muito tempo e é claro, sim, em todos os eventos que você participa isso vem à tona também [...] São divulgados. O problema dos municípios não são os prazos, são os recursos pra poder atingir a Política [risos]. [M5]

Questionando o MMA sobre as formas de acesso às informações técnicas e aos recursos para implementação das ações, G1 e G2 destacam as seguintes possibilidades:

O município, ele tem que apresentar o plano para a Caixa Econômica, com ações, programas, metas, prazos, tudo estabelecidos. [G1]

Neste ano de 2013 o sistema tradicional de aporte de recursos para elaboração dos Planos estará aberto apenas para Emendas Parlamentares. Será aplicado, com as adaptações necessárias, o sistema utilizado no estado do Amazonas com grande sucesso, onde do total de 62 municípios no estado, 59 Planos Municipais foram elaborados sem recursos da União. O sistema utiliza como entidade principal uma associação estadual de municípios [...] Para alcançar os municípios de modo geral, porque muitos estarão fora deste sistema, a EaD será a forma de capacitá-los a elaborar seus Planos Municipais sem grandes custos. [G2]

Entretanto os gestores municipais revelam, em sua grande parte, dificuldades quanto ao entendimento de informações técnicas, sendo necessária muitas vezes a contratação de empresas de consultorias para realizar o levantamento de informação sobre o volume de resíduos na cidade, por exemplo. Tal ação, além de não ser eficiente no campo econômico, pode influenciar a criação de diretrizes que não se adequam à realidade do município. Outro fator que chama atenção na perspectiva dos governantes é o desconhecimento das formas de acesso aos recursos provenientes da União. Tal fato impossibilita qualquer atividade, ficando os municípios em busca de recursos provenientes de outras fontes, como o Comitê de Integração da Bacia Hidrográfica do Rio Paraíba do Sul (Ceivap) e a Fundação Nacional de Saúde (Funasa).

A análise dos canais de feedback entre governo e sociedade revelou certa dificuldade do MMA ao particularizar a informação junto aos gestores municipais, conforme relatado:

${ }^{1}$ O Minas Sem Lixões apoia os municípios na implementação de políticas públicas voltadas para a gestão adequada dos resíduos sólidos urbanos, em um compromisso com a melhoria da qualidade ambiental do estado (Minas Sem Lixões, 2015). 
O Ministério não criou um canal específico para atendimento aos prefeitos não. O Ministério trabalha na perspectiva do todo, né, a população como um todo, qualquer pessoa pode ter acesso a qualquer tipo de informação, tendo necessidade. [...] qualquer pessoa pode acessar o site do ministério, da Ascom, da assessoria de comunicação, ou até mesmo dos próprios departamentos [...]. [G1]

Assim, o MMA peca ao entender que a comunicação governamental sobre essa política pública deva ser desenvolvida na "perspectiva do todo", sem levar em consideração as particularidades de gestão das prefeituras, a indisponibilidade de infraestrutura nos pequenos municípios e as pluralidades de "Brasis" existentes. Os entrevistados em nível municipal consideraram em sua maioria o Sinis e em alguns casos os Sinir como os principais canais de feedback com o MMA. Tal perspectiva é preocupante, uma vez que tais espaços não são formados como meio para feedback e espaço de interação, mas, sim, como meio para reunião de informações técnicas (Cezar, Barbosa e Reis, 2013). A evidência exposta aqui se molda sobre a pressuposição de uma comunicação engessada, reforçando a existência de uma política com características top-down.

Ao se verificar a ocorrência de canais de feedback dos governos municipais para com seus munícipes, observa-se uma tendência em utilizar informações via rádio e palestras realizadas pelos próprios gestores ou por membros de sua equipe. Na contramão desse contato particularizado, o MMA utiliza-se de grande parte da internet como veículo para efetivação da comunicação.

\subsubsection{OPERACIONALIZAÇÃO}

A análise sobre a adequabilidade de mídia ante o público-alvo pode ser entendida a partir da análise em relação aos parâmetros de divulgação, avaliação e aspectos de influência. Inicialmente, a investigação sobre as formas de divulgação da PNRS revelou um predomínio quanto ao uso de mídia impressa e de redes sociais, como relatado nos discursos de G1 e G2:

[...] veículos de circulação, mídia impressa principalmente, as matérias são publicadas no site do Ministério do Meio Ambiente [...] a gente fez um plano de comunicação pra dar mais visibilidade às questões da conferência [...] tem esse jornal impresso, tem artigos pra publicação [...] rádio também é uma estratégia importante que a gente tá começando a utilizar [...] a gente tem um mailing de impressa que cobre, um mailing nacional, que cobre o veículo impresso, televisivo, assessorias de imprensa, no qual a gente manda as informações [...] tem o Facebook, Twitter, e-mail, telefone e o Flickr que é um canal pra fotos. [G1]

[...] Campanha "Separe o lixo e acerte na lata" veiculada na TV, publicação de três folders sobre resíduos sólidos e do "Manual de Orientação - Plano Gestão integrada de resíduos sólidos", notícias inseridas no sítio da internet do MMA, Seminários, audiências públicas para elaboração do Plano Nacional de resíduos sólidos etc. [G2]

Ainda que existam um planejamento no setor de comunicação do MMA e uma busca em relação à divulgação por etapas e criação de campanhas sobre essas etapas, observa-se, como salientado, uma falta de preocupação com as particularidades dos municípios em estudo. A comunicação em sua 
perspectiva totalizante entende que todos os municípios tenham a mesma infraestrutura e recebam a informação da mesma forma. Obviamente, um município de menor porte tem amplas dificuldades no quesito comunicação, que não é vivenciada muitas vezes por um grande município. Na perspectiva dos gestores, há uma demanda por veículos de comunicação que sejam condizentes ao encontrado nas secretarias, como exposto nos discursos seguintes:

Então, a rede social a gente tem acesso, né, nos notebooks dos funcionários a gente acessa o Facebook, os demais são bloqueados, né, a rede social aqui é tudo bloqueado [...]. [M1]

[...] a gente não pode entrar em Facebook [...] a Jornalista tem acesso pra acompanhar alguma coisa $[\ldots] .[\mathrm{M} 2]$

[...] Não conheço a página do Facebook do Ministério. [...] Acesso nós temos [...]. [M3]

Como salientado por M1 e M2, as páginas de Facebook ${ }^{\circledR}$ e demais redes sociais são bloqueadas no local de trabalho. Uma vez que o MMA disponibiliza grande parte desse conteúdo nas redes sociais, observa-se uma assimetria de informação dada que a mesma não está direcionada à parte do público de interesse. Por outro lado, o discurso de M3 revela o desconhecimento da página do Facebook ${ }^{\circledR}$ administrada pelo MMA, ainda que este tenha acesso liberado no local de trabalho. Tal fato evidencia a necessidade de divulgação dos mecanismos de comunicação e interação da PNRS.

Grande parte dos gestores entrevistados enfatiza a importância da mídia impressa para o conhecimento a respeito de diversas informações, principalmente as de cunho técnico:

Eu acho que poderia ter, usar muito mais. É o que eu te falei, a gente acha porque "futrica", porque vir assim, de bandeja, não vem [...] por que que não chega pelo menos um e-mail assim, uma cartilha, cartilha descomplicada, sei lá, uma coisa assim, que pudesse? Tem tanta mídia disponível. [M4]

[...] está lá disponível, mas é, é aquela coisa, você tem que acessar, não é aquela coisa que chega muito pronto assim. [...] Especificamente sobre a política eu acho que tem disponível mas eu acho que ainda é difícil o acesso de muitos assim. Vêm mais a nível estadual [...]. [M5]

Conforme exposto nas cartilhas, jornais e demais documentos disponibilizados pelo MMA, a informação presente nesses materiais é rica em detalhes e apresenta os principais desdobramentos para implementação da PNRS; no entanto, a preocupação dos gestores recai na indisponibilidade de material impresso suficiente para o público interno e para os munícipes, tornando necessária a busca de informações em diversos sites sem fontes confiáveis. Assim, como apontado, há necessidade de que a informação em nível federal chegue de forma mais eficiente, com uma linguagem mais clara e que não tenha necessidade de ser solicitada pelos gestores municipais.

Questionados sobre aspectos que influenciam positiva e negativamente a comunicação da PNRS, os representantes do MMA destacam fatores para além da comunicação governamental, conforme observa-se nos discursos: 
[...] um fator que limita muitas vezes é a falta de efetividade da política né, no processo de implementação dessa política no município ou naquele estado. E isso instabiliza a comunicação. Como é que a gente vai comunicar o que não está acontecendo? Ou o que não está acontecendo da maneira certa? O município que não está fazendo seu dever de casa, fica difícil da gente também divulgar. A gente não divulgar o que é ruim. [G1]

Informações consolidadas sobre situação dos resíduos sólidos nos entes federados, divulgação da Lei oㅡ 12.305/2010 e das medidas adotadas, falta de técnicos capacitados principalmente nos municípios, recursos insuficientes e desinteresse dos gestores municipais antecessores dos atuais. [G2]

De acordo com G1 e G2, grande parte da dificuldade em se comunicar recai no curso da política que ainda não foi implementada em totalidade, devida muitas vezes à ineficiência dos municípios em realizar suas obrigações. Há, assim, uma preocupação do MMA em não divulgar informações de caráter desmotivador aos demais. Complementarmente, o conjunto de questões técnicas levantadas por G2 revela a necessidade de maiores investimentos em todas as suas dimensões.

A perspectiva levantada pelos gestores municipais, além de apresentar os principais pontos positivos e negativos, tanto da PNRS como de seu modelo de comunicação, aponta alternativas descritas aqui como caminhos para o MMA buscar uma comunicação mais eficiente e eficaz. A síntese de tais discursos pode ser observada na figura 3.

\section{FIGURA 3 PONTOS POSITIVOS, PONTOS NEGATIVOS E ALTERNATIVAS}

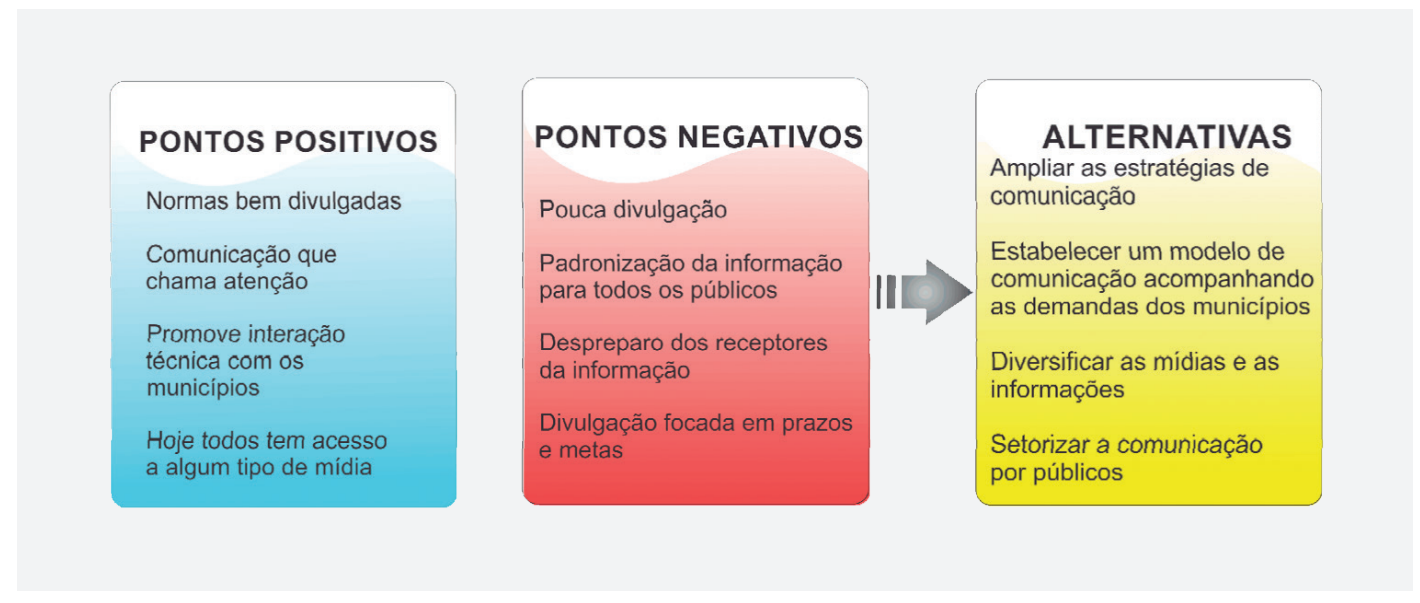

Fonte: Cezar (2014).

Os gestores apontam a não padronização das mídias, do público e das informações como o caminho a ser modificado, visando atender as principais demandas. Tal ação, além de proporcionar um canal desenvolvido para cada região brasileira, poderia facilitar a fluidez tanto no repasse, quanto na criação de arenas de participação e comunicação. 


\section{CONSIDERAÇÕES FINAIS}

A comunicação governamental em suas diferentes esferas adquire elementos que ultrapassam a mera formalidade do campo funcionalista da comunicação organizacional. Ao permitir um olhar para além dos muros organizacionais, a comunicação alcança o espaço público e torna-se responsabilidade não somente de seus formuladores e receptores, mas de um conjunto de atores que se manifestam em diferentes espaços. Assim, entender a comunicação em seu âmbito público configura-se como algo promissor no campo de estudos organizacionais e da administração pública ao permitir uma análise imbuída de elementos advindos da gestão pública e da comunicação.

O modelo de análise proposto neste trabalho agrupa, em diferentes esferas, elementos que, ante os atuais modelos de avaliação da comunicação organizacional e comunicação de caráter mobilizador propostos, respectivamente, por Galerani (2006) e Henriques e colaboradores (2002), avançam ao criarem uma metodologia que possa ser aplicada em diferentes dimensões para avaliação da comunicação em políticas públicas. Cabe ressaltar que o modelo não pretende esgotar as discussões, mas inaugurar possibilidades para criação de novas perspectivas de pesquisas que entendam no campo de políticas públicas a presença da comunicação como fator de extrema importância de análise.

Assim, a validação realizada no trabalho de Cezar (2014) revela a dificuldade de comunicação do MMA com os gestores municipais da Zona da Mata de Minas Gerais a respeito da PNRS. Os parâmetros de publicização evidenciaram o caráter de publicização fraca, uma vez que, ainda que existam possibilidades criadas pelo MMA para publicização de informações, inserindo o público-alvo nos contextos democráticos, essa oportunidade não é eficiente. A análise quanto à formalização revelou que a estratégia de comunicação utilizada pelo governo atinge em partes seu objetivo, principalmente na divulgação de prazos e metas que são amplamente conhecidos pelos gestores; todavia, a falta de acesso às informações via redes sociais e a não ocorrência de canais de feedback específicos dificultam maiores resultados. Por fim, a interpretação do quesito operacionalização permite-nos afirmar que o conjunto de mídias utilizadas pelo MMA não atende às demandas dos respondentes, seja por dificuldade de acesso interno ou pela escassez na disponibilização de material impresso.

Assim, cabe assumir que a comunicação governamental da PNRS pode ser considerada eficiente em alguns pontos, uma vez que as principais informações da política são compreendidas pelos gestores entrevistados; todavia, as metas do governo federal quanto à busca de capacitação e atendimento em totalidade dos gestores para atendimento ao prazo final da política ( 2 de agosto de 2014) não ocorreram, comprometendo assim a eficácia da comunicação. A visão do NPM mostra-se fragilizada para atender a essa realidade, uma vez que a busca por espaços comunicacionais moldados a partir da participação popular revela-se como a veia pulsante da referida política pública.

No intuito de ampliar as discussões nessa temática, estudos que compreendam o papel da comunicação governamental em outras políticas públicas, bem como investigações sobre as formas de participação popular em face das métricas preconizadas pelo NPM, podem contribuir para a construção de novas arenas de debate. 


\section{REFERÊNCIAS}

ABREU, Ana C. D.; HELOU, Angela R. H. A.; FIALHO, Francisco A. P. Possibilidades epistemológicas para a ampliação da teoria da administração pública: uma análise a partir do conceito do novo serviço público. Cad.EBAPE.BR, Rio de Janeiro, v. 11, n. 4, p. 608-620, 2013.

ANSELL, Chris; GASH, Alison. Collaborative governance in theory and practice. Journal of Public Administration Research and Theory, v. 18, n. 4, p. 543-571, 2008.

ARENDT, Hannah. A condição humana. São Paulo: Forense-Universitária, 2007.

BARDIN, Laurence. Análise de conteúdo. Lisboa: Edições 70, 1977.

BOHMAN, James. O que é deliberação pública? Uma abordagem dialógica. In: MARQUES, Ângela C. S. (Org.). A deliberação pública e suas dimensões políticas e comunicacionais: textos fundamentais. Belo Horizonte: Autêntica, 2009.

BRANDÃO, Elizabeth P. Conceito de comunicação pública. In: DUARTE, Jorge. Comunicação pública: estado, mercado, sociedade e interesse público. 2. ed. São Paulo: Atlas, 2009.

BRASIL. Constituição. Constituição da República Federativa do Brasil. Brasília, DF: Senado Federal, 1988.

BRASIL. Ministério do Meio Ambiente. Apresentação. Disponível em: <www.mma.gov.br/o-ministerio/apresentacao>. Acesso em: 4 dez. 2013.

CEZAR, Layon C. Análise da comunicação governamental sobre a Política Nacional de Resíduos Sólidos na Zona da Mata Mineira. Dissertação (mestrado em administração) - Universidade Federal de Viçosa, Viçosa, 2014.

CEZAR, Layon C.; BARBOSA, Telma R. C. G.; REIS, Maria C. T. Interfaces da comunicação pública e governamental na divulgação da política nacional dos resíduos sólidos. Revista de Ciências Humanas, Viçosa, v. 13, n. 1, p. 102-120, 2013.

CEZAR, Layon C. et al. Por uma esfera pública efetivamente publicizada: reflexões sobre a participação de gestores municipais na Política Nacional de Resíduos Sólidos. Revista Pretexto, v. 17, n. 1, p. 83-98, 2016.
DUARTE, Marcia Y. M. Comunicação e cidadania. In: DUARTE, Jorge. Comunicação Pública: Estado, mercado, sociedade e interesse público. 2. ed. São Paulo: Atlas, 2009.

GALERANI, Gilceana S. M. Avaliação em comunicação organizacional. Brasília, DF: Embrapa, 2006.

GIL, Antônio C. Como elaborar projetos de pesquisa. 3. ed. São Paulo: Atlas, 1991.

GOMES, Wilson. Esfera pública política e mídia. Com Habermas, contra Habermas. In: RUBIM, Antônio A. (Org.). Produção e recepção dos sentidos midiáticos. Petrópolis: Vozes, 1998. p. 155-185.

HABERMAS, Jürgen. Moral consciousness and communicative action. Cambridge: MIT Press, 1990.

HABERMAS, Jürgen. Mudança estrutural da esfera pública: investigações quanto a uma categoria da sociedade burguesa. Rio de Janeiro: Tempo Brasileiro, 1984.

HENRIQUES, Márcio S. et al. Comunicação e estratégias de mobilização social. Belo Horizonte: Genesis, 2002.

HOOD, Christopher. The "new public management" in the 1989s: variations on a theme. Accounting Organizations and Society, v. 20, n. 2/3, p. 93-109, 1995.

HUGHES, Owen. Does governance exist? In: OSBORNE, Stephen P. (Ed.). The new public governance. Londres: Routledge, 2010. p. 87-104.

IBGE. Instituto Brasileiro de Geografia e Estatística. Censo demográfico 2010. Disponível em: <www. ibge.gov.br/home/estatistica/populacao/censo2010/ calendario.shtm >. Acesso em: 11 mar. 2013.

MINAS SEM LIXÕES. Compromisso com a sustentabilidade: ações e metas do Minas Sem Lixões. Disponível em: <www.minassemlixoes.org.br/ conheca-o-programa/quem-somos/>. Acesso em: 5 maio 2015.

OSBORNE, David; GLAEBER, Ted. Reinventing government: how the entrepreneurial spirit is transforming the public sector. Nova York: Penguin Books, 1992.

OSBORNE, Stephen. The new public governance? Public Management Review, v. 8, n. 3, p. 377-387, 2006. 
SALDANHA, Clezio. Introdução à gestão pública. São Paulo: Saraiva, 2006.

SANTOS, Antônio R. dos. Metodologia científica: a construção do conhecimento. 3. ed. Rio de Janeiro: DP\&A, 2000.

SANTOS, Mireli M. S. dos; FORMENTINI, Marcia. A complexidade na avaliação da comunicação organizacional. In: CONGRESSO DE CIÊNCIAS DA COMUNICAÇÃO NA REGIÃO SUL-INTERCOM, $\mathrm{X}, 2009$, Blumenau.

SOUZA, Celina. Políticas públicas: uma revisão de literatura. Sociologias, v. 8, n.16, p. 20-45, 2006.
STOKER, Gerry. Governance as theory: five propositions. International Social Science Journal, v. 50, n. 1, p. 17-28, 1998.

TORQUATO, Gaudêncio. Da gênese do jornalismo empresarial e das relações públicas à comunicação organizacional no Brasil. In: KUNSCH, Margarida M. K. (Org.). Comunicação organizacional: histórico, fundamentos e processos. v. 1. São Paulo: Saraiva, 2009. p. 7-28.

VOS, Marita. Setting the research agenda for governmental communication. Journal of Communication Management, v. 10, n. 3, p. 250-258, 2006.

\section{Layon Carlos Cezar}

Professor assistente do Instituto de Ciências Sociais Aplicadas da Universidade Federal de Alfenas. Doutorando em administração pela Universidade Federal do Espírito Santo. Mestre em administração e bacharel em gestão de cooperativas pela Universidade Federal de Viçosa e bacharel em administração pela Universidade Federal Rural do Rio de Janeiro. E-mail: layoncezar@gmail.com. 